\section{References}

Ashworth A (1969) Growth rates in children recovering from protein-calorie malnutrition. British Journal of Nutrition 23, 835-845.

Dulloo AG (1997a) Regulation of body composition during weight recovery: integrating control of energy-partitioning and thermogenesis. Clinical Nutrition 16, Suppl. 1, 25-35.

Dulloo AG (1997b) Human pattern of hyperphagia and fuel partitioning during weight recovery after starvation: a theory of autoregulation of body composition. Proceedings of the Nutrition Society 56, 25-40.

Dulloo AG \& Girardier L (1990) Adaptive changes in energy expenditure during refeeding following low calorie intake: evidence for a specific metabolic component favouring fat storage. American Journal of Clinical Nutrition 52, 415-420.

Dulloo AG, Jacquet J \& Girardier L (1996) Autoregulation of body composition during weight recovery in human: the Minnesota Experiment revisited. International Journal of Obesity 20, 393-405.

Dulloo AG, Jacquet J \& Girardier L (1997) Poststarvation hyperphagia and body fat overshooting in humans: a role for feedback signals from lean and fat tissues. American Journal of Clinical Nutrition 65, 717- 723.
Henry CJK, Payne PR \& Ghusain-Choueiri A (1997) Relationship between tissue mobilization and storage in the rat. British Journal of Nutrition 78, 131-141.

Keys A, Brozek J, Henchel A, Michelsen O \& Taylor HL (1950) The Biology of Human Starvation. Minnesota: University of Minnesota Press.

MacLean WC \& Graham GG (1980) The effect of energy intake on nitrogen content of weight gained by recovering malnourished infant. American Joumal of Clinical Nutrition 33, 903 909.

Payne PR \& Dugdale AE (1977) A model for the prediction of energy balance and body weight. Annals of Human Biology 4 , 525-535.

Reeds PJ, Jackson AA, Picou D \& Poulter N (1978) Muscle mass and composition in malnourished infants and children and changes seen after recovery. Pediatric Research 12, 613-618.

A. G. Dulloo

Department of Physiology

Faculty of Medicine

University of Geneva

1211 Geneva 4

Switzerland

\title{
Energy partitioning between body storage of protein and fat during starvation and refeeding: sources of intra-individual variation of P-ratios - Reply by Henry et al.
}

We read with great interest the comments made by Dulloo (1998) in response to our paper (Henry et al. 1997). We are entirely in agreement that the partitioning of stored energy between lean and fat tissue compartments is an individual characteristic. This characteristic is probably genetically determined and serves, as Dulloo et al. (1996) have described, as a metabolic 'memory' for a preferred set of body tissue proportions.

However, we beg to differ with the inferences Dulloo has drawn from a comparison between the results from our experiments and those of his own. We suspect that divergence of views is as much the result of semantic problems as of any fundamental conceptual conflict. We, therefore, will try once more to express our position as carefully as possible.

1. In the computer model of adult body weight regulation, Payne \& Dugdale (1977) made three assumptions. One of those was that for a given individual there would always be close equality between the proportion of energy withdrawn from tissues in the form of protein $\left(P_{\text {fast }}\right)$, during negative energy balance and the corresponding proportion deposited during positive balance $\left(\mathrm{P}_{\text {refed }}\right)$. It is important to recognize that the long-term stability of the model depends on this condition being applied to the calculation of day-to-day changes in energy balance. These changes are then summed over time, and then used to predict longer-term weight variations. The key assumption, therefore, is the short-term equality of $P_{\text {fast }}$ and $P_{\text {refed. For practical reasons, how- }}$ ever, actual measurements of P-ratios usually have to be made over time periods substantially longer than one day.
2. It is likely that changes in the absolute values of $P_{\text {fast }}$ and $P_{\text {refed }}$ will occur in response to changes of energetic efficiency and body composition throughout growth, reproductive activity and senescence. Indeed, Dugdale \& Payne (1975) had already pointed out that the partition of stored energy in individual human infants swings rapidly and repeatedly over a manifold range, during the first months of life. Needless to say that other environmental and metabolic insults are also likely to bring changes in the absolute values of $P_{\text {fast }}$ and $P_{\text {refed }}$.

3. The objectives of our recent work have therefore been: (i) to quantify some of the changes in P-ratios throughout growth and development; (ii) to assess the degree to which $\mathrm{P}_{\text {fast }}$ and $\mathrm{P}_{\text {refed }}$ remained equal despite those changes (by measuring them sequentially in the same individuals, using periods of time kept as short as possible); (iii) to test the hypothesis that despite changes in the average ratios of groups of individuals intra-individual differences are still maintained. We reported only partial success: P-ratios measured during fasting in older but still slowly-growing rats were not significantly different from those measured during subsequent refeeding. Intra-individual differences were sustained throughout the measurements, in both weanling and the older animals. However, we found a major inequality between $P_{\text {fast }}$ and $P_{\text {refed }}$ in the weanling animals. The average ratio measured during a $3 \mathrm{~d}$ fast at the midpoint-age of $31 \mathrm{~d}$ was followed by a value three-fold higher, during subsequent refeeding, at a mid-point-age of $41 \mathrm{~d}$. This effect is the reverse of the differences shown in Dulloo's Table 1 (p. 108). There the values for $P_{\text {refed }}$ derived from cross-sectional measurements on 
older but still growing rats are lower after a period of semi-starvation, than those for ad libitum-fed controls. Dulloo et al. (1996) interpreted this as the result of compensatory adaptation to the period of depletion.

It is useful to be able to draw upon Dulloo's comments and the figures provided in Table 1, to throw some light on what is clearly a complex situation. At mid-point age of $72 \mathrm{~d}$ the rats studies by Dulloo \& Girardier (1990) were at a stage of life intermediate between our weanling and adult (136 d) females. Both the magnitudes of the P-ratios and the effects of underfeeding differ from ours. We can identify some possibilities for the discrepancies.

First, a part (all-be-it small) results from the method of calculation. In the 1990 paper the results are not expressed as P-ratios, but as separate estimates of incremental changes in stored protein and fat, expressed as gross energy $(9.22 \mathrm{kcal} / \mathrm{g}$ for fat and $5.42 \mathrm{kcal} / \mathrm{g}$ for protein). It appears that for the 1996 paper these were used directly to compute P-ratios. However, Payne \& Dugdale (1977) chose to define P-ratios in terms of metabolizable energy (using the conventional factors 9.0 and 4.0 , or their SI equivalents). We have adhered to that convention, which results in a significant difference, particularly at lower values of the ratio. Recalculation suggests that to put the figures in Table 1 on a comparable basis, those for refeeding should be 0.25 , for weight-matched controls 0.38 , and for agematched controls $0 \cdot 43$.

Second, differences in experimental design are likely to be of greater significance. Dulloo \& Girardier (1990) did not make any measurements during the fasting period, regarding this as a means of 'pre-conditioning' the animals. Thus, their results cannot contribute to our interest in the question of the short-term equality between $P_{\text {fast }}$ and $P_{\text {refed }}$. The $10 \mathrm{~d}$ food-restriction period resulted in a body-weight loss of $30 \%$ (compared to $15 \%$ in our adult rats). One consequence of this large weight loss was the problem familiar to cross-sectional studies, i.e. that of matching controls. The age-matched controls were $30 \%$ heavier by the time of the energy balance measurements, whereas the weight-matched controls were obtained by selection from a younger cohort of ad libitum-fed animals. Enough has been said above regarding the existence of individual variability to raise serious questions regarding the effect of such selection on the representativeness of the resulting sample population.

This should not, however, be taken as a dismissal of the possibility that P-ratios can show adaptive changes. On the contrary, we need to know more about the effects of dietary and other biological stresses. For example, how long does it take to establish adaptive responses? How reversible are they? Do they affect both $\mathrm{P}_{\text {fast }}$ and $\mathrm{P}_{\text {refed }}$ ? At the same time we are sufficiently alive to the puzzling consequences of our own choice of $30-40 \mathrm{~d}$ of age (for the longitudinal sequence of measurements on weanling rats) to understand that we must have more information about the pattern of age-related changes in the P-ratio. Our next approach to the problem of establishing the pattern of age changes will, therefore, be based on the use of time-series analysis. Applying this to an extended sequence of measurements of body fat and protein content of normally-fed rats from birth to maturity (unpublished data) suggested that young rats exhibit at least two large, transient peaks of predominantly lean tissue deposition (i.e. high P-ratios). The first peak is at its maximum around $35 \mathrm{~d}$ of age. Our experimental design, with its sequential measurements spanning the period 30 $50 \mathrm{~d}$, may well have been confounded by the much lower values preceding and following that peak. The second peak occurs at around $70 \mathrm{~d}$, i.e. within the 59-94 d period of the observations of Dulloo \& Girardier (1990).

The figures in Table 1 (p. 108) were derived from the excellent revisit by Dulloo et al. (1996) to the data from the Minnesota Experiment. We find it hardly surprising that estimates of $P_{\text {refed }}$ made after the subjects lost $40 \%$ of their initial body weight differed significantly from those of $\mathrm{P}_{\text {fast }}$ made during the first period of fasting. However, in view of the wide range of the data, and the assumptions regarding tissue composition and energy values involved, we would be cautious of accepting the statistical validity of anything beyond the general direction of the change. Indeed, it is perhaps surprising that the magnitude of the adaptation suggested is so small, given that P-ratios significantly $<0.1$ are found at the lower end of the range for human populations. Certainly, it was something of a surprise to Payne and Dugdale that the model gave such convincing simulations of the observed weight changes throughout the entire period, including the first stages of recovery.

\section{References}

Dugdale AE \& Payne PR (1975) Pattern of fat and lean tissue deposition in children. Nature 256, 725-727.

Dulloo AG (1998) Partitioning between protein and fat during starvation and refeeding: is the assumption of intra-individual constancy of P-ratio valid? (Letter). British Journal of Nutrition, 79, 107-109.

Dulloo AG \& Girardier L (1990) Adaptive changes in energy expenditure during refeeding following low calorie intake: evidence for a specific metabolic component favouring fat storage. American Journal of Clinical Nutrition 52, 415-420.

Dulloo AG, Jacquet J \& Girardier L (1996) Autoregulation of body composition during weight recovery in human: the Minnesota Experiment revisited. International Journal of Obesity 20, 393-405.

Henry CJK, Payne PR \& Ghusain-Choueiri A (1997) Relationship between tissue mobilization and storage in the rat. British Journal of Nutrition 78, 131-141.

Payne PR \& Dugdale AE (1977) A model for the prediction of energy balance and body weight. Annals of Human Biology 4, 525-535.

C. J. K. Henry and A. Ghusain-Choueiri School of Biological \& Molecular Biology Oxford Brookes University Oxford OX3 OBP United Kingdom

P. R. Payne London School of Hygiene and Tropical Medicine 2 Taviton Street London WC1H OBT United Kingdom 